\title{
One year into the SARS-CoV-2 pandemic: perinatal outcome and data on the transmission of 116 pregnant women
}

https://doi.org/10.1515/jpm-2021-0271

Received May 26, 2021; accepted January 13, 2022;

published online February 1, 2022

\section{Abstract}

Objectives: Report of clinical data on maternal outcomes, mode of delivery and immediate neonatal outcome in women infected with COVID-19, as well as clarifying whether the transmission of SARS-CoV-2 could occur in utero (congenital), intrapartum, and/or postnatally through breastmilk, amniotic fluid or cord blood.

Methods: Retrospective data collection. Evidence of vertical transmission was assessed by testing for SARS-CoV-2 in amniotic fluid, cord blood, maternal liquor, breast milk and neonatal pharyngeal swab samples.

Results: $8.9 \%(n=8)$ of the total population of hospitalized SARS-CoV-2 positive pregnant women were admitted to a critical care unit, one $(0.9 \%)$ needed extracorporal membrane oxygenation (ECMO) and one woman died (0.9\%). The premature birth rate before $34+0$ weeks of gestational age of $8.2 \%(n=8)$ among pregnant women who tested positive for SARS-CoV-2, was almost four times higher than among the total population of pregnant women in Austria. Two newborns (2\%) were tested positive for SARS-CoV-2 after birth. No SARS-CoV-2 was found in amniotic fluid, cord blood, maternal liquor or breast milk using polymerase chain reaction (PCR).

Conclusions: Pregnant women with COVID-19 seem to be at a higher risk of invasive ventilation, admission to a critical care unit and pre-term birth and therefore they should be considered as a high-risk population. The risk of congenital or intrapartal infection seems to be insignificant.

*Corresponding author: Dr. Med. Univ. Mirijam Hall, Abteilung für Gynäkologie und Geburtshilfe, Wiener Gesundheitsverbund - Klinik Ottakring, Montleartstr. 37, 1160 Vienna, Austria, E-mail: mirijam.hall@gesundheitsverbund.at. https://orcid.org/ 0000-0002-2457-6544

Susanne Hölbfer, David Endress, Gabriele Aicher, Georg DrechselBurkhard and Barbara Maier, Abteilung für Gynäkologie und Geburtshilfe, Wiener Gesundheitsverbund - Klinik Ottakring, Vienna, Austria
Keywords: COVID-19; maternal outcome; neonatal outcome; pregnancy; SARS-CoV-2; transmission.

\section{Introduction}

The Department of Gynecology and Obstetrics in the Clinic Ottakring is the COVID-19 specialized obstetric department for Vienna and it has treated 98 women who tested positive for SARS-CoV-2 while giving birth, and 18 pregnant women who needed hospitalization but could be discharged still pregnant after recovery from COVID-19 until April 2021. A standard operating procedure was established early into the pandemic and subsequently updated more than 10 times to reflect the latest scientific findings on pregnant women as a high-risk group [1-5]. Based on these findings and earlier publications on the perinatal outcome in the Clinic Ottakring [6], pregnant women are now considered a high-risk group in Austria and therefore they have been prioritised in terms of access to vaccinations against COVID-19 by the National Vaccination Board [7].

Despite reports of neonatal COVID-19, SARS-CoV-2 has not been consistently isolated in perinatal samples and there is inconclusive evidence regarding congenital, intrapartum, and postnatal maternal-fetal-neonatal SARS-CoV-2 infections [8, 9].

As we are still learning in the context of the ongoing pandemic, especially about the effects of infections on the mother, pregnancy and child, data on infection-rates, clinical outcomes and transmission is key to the most effective perinatal care.

\section{Materials and methods}

Clinical data was collected for 118 pregnant women who tested positive for SARS-CoV-2 and were hospitalized between May 2020 and April 2021 in the Clinic Ottakring. Evidence of vertical transmission was assessed by testing for SARS-CoV-2 in amniotic fluid, cord blood, and neonatal pharyngeal swab samples. Informed consent was obtained from all individuals included in this study. 


\section{Results}

A total of 118 women eligible for the study were hospitalized in the Clinic Ottakring, among whom 98 women delivered during their hospitalization, and 18 women could be discharged still pregnant after recovery from COVID-19. All participants were tested positive for SARS-CoV-2 using polymerase chain reaction (PCR). Most women ( $\mathrm{n}=83$; $70.3 \%)$ were asymptomatic. $19.5 \%(\mathrm{n}=23)$ of the pregnant women who tested positive for SARS-CoV-2 and were hospitalized at the Clinic Ottakring needed hospitalization primarily because of their COVID-19 symptoms. Sixteen patients $(8.6 \%)$ required oxygen support, eight $(6.9 \%)$ were admitted to a critical care unit and six of them needed intubation $(5.2 \%)$. This means that $22.9 \%(n=8)$ of all women who showed symptoms required critical care. One intubated woman had to be transferred for extracorporeal membrane oxygenation (ECMO), and one patient died due to her critical condition caused by COVID-19 eight days after cesarean section at $31+6$ gestational weeks. The characteristics of the population are shown in Table 1.

Swabs of the amniotic fluid of 45 women were collected. Furthermore, we were able to collect 53 swabs of cord blood and 44 swabs of breast milk. In 13 patients,

Table 1: Characteristics of the population.

\begin{tabular}{|c|c|c|c|}
\hline & $\begin{array}{l}\text { Total population } \\
\text { of hospitalized } \\
\text { SARS-CoV-2- } \\
\text { positive preg- } \\
\text { nant women } \\
\text { n=118 }\end{array}$ & $\begin{array}{l}\text { Women who } \\
\text { delivered while } \\
\text { SARS-CoV-2- } \\
\text { positive } \\
\text { n=98 }\end{array}$ & $\begin{array}{l}\text { SARS-CoV- } \\
\text { 2-positive } \\
\text { women dis- } \\
\text { charged while } \\
\text { still pregnant } \\
n=18\end{array}$ \\
\hline $\begin{array}{l}\text { Mean age, } \\
\text { years }\end{array}$ & $30.5(17-43)$ & $30.7(19-40)$ & $29.4(17-43)$ \\
\hline $\begin{array}{l}\text { Median gesta- } \\
\text { tional week, } \\
\text { when tested } \\
\text { positive }\end{array}$ & $39+1$ weeks & $39+5$ weeks & $29+5$ weeks \\
\hline $\begin{array}{l}\text { COVID-19 } \\
\text { symptoms }\end{array}$ & 35 (29.7\%) & $22(22.45 \%)$ & $13(72.0 \%)$ \\
\hline $\begin{array}{l}\text { Hospitalized } \\
\text { because of } \\
\text { COVID-19 } \\
\text { symptoms }\end{array}$ & 23 (19.5\%) & $10(10.2 \%)$ & $13(72.0 \%)$ \\
\hline Intensive care & $8(8.9 \%)$ & 7 (7.1\%) & $1(5.6 \%)$ \\
\hline Intubation & $6(5.1 \%)$ & $6(6.1 \%)$ & 0 \\
\hline ECMO & $1(0.9 \%)$ & $1(1.0 \%)$ & 0 \\
\hline $\begin{array}{l}\text { Non-invasive } \\
\text { ventilation }\end{array}$ & $2(1.7 \%)$ & $1(1.0 \%)$ & $1(5.6 \%)$ \\
\hline Death & $1(0.9 \%)$ & $1(1.0 \%)$ & 0 \\
\hline
\end{tabular}

ECMO, extracorporeal membrane oxygenation. swabs of maternal liquor were collected during spinal anesthesia. All 155 samples were tested for SARS-CoV-2 using polymerase chain reaction (PCR). Although two newborns tested positive for SARS-CoV-2 after birth, there was no virus found in any of the collected samples of amnion fluid, cord blood, breast milk or maternal liquor. The results of the histological examination of placental tissue - which was also collected - are still pending.

In $44(44.9 \%)$ cases, a cesarean section had to be performed, and in eight cases the reason for the cesarean section was the mother's critical condition due to COVID-19 disease. In nine cases $(9.2 \%)$, a vacuum extraction was performed, in seven cases due to pathological cardiotocography (CTG), and in two cases due to arrested labor. Fifteen births were induced, and in five of these cases a secondary cesarean section was necessary.

All newborns $(\mathrm{n}=100)$ were tested for SARS-CoV-2 multiple times after birth, and the tests immediately after birth were all negative. Two newborns (2\%) tested positive for SARS-CoV-2 on the second day after birth, one (1\%) developed a pneumonia and needed high flow oxygen and systemic corticosteroids, while the other only presented fever up to $38.5^{\circ} \mathrm{C}$. Pre-term birth before 34 weeks of gestational age occurred in eight cases (8.2\%) and therefore was almost four times higher than among the total population of pregnant women in Austria [10]. In all such cases an elective cesarean section was performed due to the mother's critical condition, and the neonates were transferred to neonatal intensive/intermediate care. The neonatal outcomes are shown in Table 2.

Table 2: Neonatal outcome.

\begin{tabular}{ll}
\hline & $\mathbf{n}=\mathbf{2 8}$ \\
\hline Mean birth weight & $3,284 \mathrm{~g}(1,045-4,360 \mathrm{~g})$ \\
Pre-term births <34 weeks & $8(8.2 \%)$ \\
Mean pH, $\mathrm{n}=22$ & 7.26 \\
$\mathrm{pH} \leq 7.10$ & $5(5.1 \%)$ \\
1 min APGAR $\leq 7$ & $14(14.3 \%)$ \\
SARS-CoV-2-positive, PCR & $2(2.0 \%)$ \\
Transfer in NIMC/NICU & $18(18.4 \%)$ (nine transferred to \\
& NICU, seven transferred to NIMC \\
& and other two transferred to NIMC \\
& only for separation at the request of \\
the mother) \\
Perinatal death & $0(0 \%)$ \\
Rooming in with mother & $80(81.6 \%)$ \\
\hline
\end{tabular}

APGAR, Apgar score; NICU, neonatal intensive care unit; NIMC, neonatal intermediate care unit; PCR, polymerase chain reaction; $\mathrm{pH}, \mathrm{pH}$ value. 


\section{Discussion}

The figures on clinical outcomes - especially pre-term delivery, admissions to critical/intensive care units and intubation were comparable with international reports [11] and our earlier results [6]. Even though our data doesn't encompass every single pregnant women in Vienna who tested positive for SARS-CoV-2, only the ones who were reffered to our clinic, the high rate of hospitalization among positive testet pregnant women in this study (19.5\%), compared to the overall hospitlisation rate in Austria for the age between 15 and 44 of 2\% [12], needs further investigation. The proportion of symptomatic women who had to be transferred to an intensive care unit (over one-fifth) is high considering that these women are young, and thus it shows how seriously COVID-19 infection must be taken among the collective of pregnant women. Early admission for close clinical controls and an early start of medication with Dexamethasone [13-15] and Remdesivir [16, 17] were established as a consequence in our clinic to meet these concerns.

Research funding: Medical Scientific Fund of the Mayor of the City of Vienna.

Author contributions: All authors have accepted responsibility for the entire content of this manuscript and approved its submission.

Competing interests: Authors state no conflict of interest. Informed consent: Informed consent was obtained from all individuals included in this study.

Ethical approval: The research related to human use has complied with all the relevant national regulations, institutional policies, and in accordance with the tenets of the Helsinki Declaration, and has been approved by the authors' Institutional Review Board (Ethikkommission der Stadt Wien, EK-20-084-VK).

\section{References}

1. Zambrano LD, Ellington S, Strid P, Galang RR, Oduyebo T, Tong VT, et al. Update: characteristics of symptomatic women of reproductive age with laboratory-confirmed SARS-CoV-2 infection by pregnancy status - United States, January 22-October 3, 2020. MMWR Morb Mortal Wkly Rep 2020;69:1641-7.

2. Klaritsch P, Ciresa-König A, Kiss H, Pristauz G. Maternale und perinatale Komplikationen bei COVID-19 während der Schwangerschaft - ein Review der Österreichischen Gesellschaft für Gynäkologie und Geburtshilfe (OEGGG); 2020. https://www. oeggg.at/app/download/9815157286/0EGGG\%20Review\% 20COVID-19\%20Update\%20271120\%20Links.pdf? $\mathrm{t}=1607613676$ [Accessed 15 Jan 2022].
3. Allotey J, Stallings E, Bonet M, Yap M, Chatterjee S, Kew T, et al. for PregCOV-19 Living Systematic Review Consortium. Clinical manifestations, risk factors, and maternal and perinatal outcomes of coronavirus disease 2019 in pregnancy: living systematic review and meta-analysis. BMJ 2020;370:m3320.

4. Pierce-Williams R, Burd J, Felder L, Khoury R, Bernstein P, Avila K, et al. Clinical course of severe and critical coronavirus disease 2019 in hospitalized pregnancies: a United States cohort study. Am J Obstet Gynecol MFM 2020;2:100134.

5. Diriba K, Awulachew E, Getu E. The effect of coronavirus infection (SARS-CoV-2, MERS-CoV, and SARS-CoV) during pregnancy and the possibility of vertical maternal-fetal transmission: a systematic review and meta-analysis. Eur J Med Res 2020;25:39.

6. Hall M, Endress D, Hölbfer S, Maier B. SARS-CoV-2 in pregnancy: maternal and perinatal outcome data of 34 pregnant women hospitalised between May and October 2020. J Perinat Med 2020; 49:138-40.

7. Bundesministerium für Soziales, Gesundheit, Pflege und Konsumentenschutz (BMSGPK) (Hg.) 2021. COVID-19-Impfungen: Anwendungsempfehlungen des Nationalen Impfgremiums, Version 4.1

8. Caparros-Gonzalez RA, Pérez-Morente MA, Hueso-Montoro C, Álvarez-Serrano MA, de la Torre-Luque A. Congenital, intrapartum and postnatal maternal-fetal-neonatal SARS-CoV-2 infections: a narrative review. Nutrients 2020;12:3570.

9. Yan J, Guo J, Fan C, Juan J, Yu X, Li J, et al. Coronavirus disease 2019 in pregnant women: a report based on 116 cases. Am J Obstet Gynecol 2020;223:111.e1-14.

10. Statistics Austria. Statistics of natural population movements. https://www.statistik.at/web_de/statistiken/menschen_und_ gesellschaft/bevoelkerung/geborene/medizinische_und_ sozialmedizinische_merkmale/066971.html [Accessed 15 Jan 2022].

11. WAPM (World Association of Perinatal Medicine) Working Group on COVID-19. Maternal and perinatal outcomes of pregnant women with SARS-CoV-2 infection. Ultrasound Obstet Gynecol 2020;57:232-41.

12. Gesundheit Österreich GmbH: Datenplattform COVID-19; COVID-19 Infizierte und -Patienten nach Alter.

13. World Health Organization. Corticosteroids for COVID-19: living guidance. https://www.who.int/publications/i/item/WHO2019-nCoV-Corticosteroids-2020.1 [Accessed 15 Jan 2022].

14. WHO Rapid Evidence Appraisal for COVID-19 Therapies (REACT) Working Group, Sterne JAC, Murthy S, Diaz JV, Slutsky AS, Villar J, et al. Association between administration of systemic corticosteroids and mortality among critically ill patients with COVID-19: a meta-analysis. JAMA 2020;324:1330-41.

15. RECOVERY Collaborative Group, Horby P, Lim WS, Emberson JR, Mafham M, Bell JL, et al. Dexamethasone in hospitalized patients with Covid-19. N Engl J Med 2021;384:693-704.

16. Spinner CD, Gottlieb RL, Criner GJ, Arribas López JR, Cattelan AM, Viladomiu AS, et al. Effect of Remdesivir vs. standard care on clinical status at 11 days in patients with moderate COVID-19: a randomized clinical trial. JAMA 2020;324:1048-57.

17. Beigel JH, Tomashek KM, Dodd LE, Mehta AK, Zingman BS, Kalil $A C$, et al. Remdesivir for the treatment of Covid-19 - final report. N Engl J Med 2020;383:1813-26. 